\title{
On the sizing of a novel Flat-Panel ground heat exchanger in coupling with a dual-source heat pump
}

\author{
M. Bottarelli ${ }^{\text {a, } *}$, M. Bortoloni ${ }^{\text {a }}, \mathrm{Y} . \mathrm{Su}^{\mathrm{b}}$ \\ ${ }^{a}$ Department of Architecture, University of Ferrara, Via Quartieri 8, Ferrara, 44121, Italy \\ ${ }^{\mathrm{b}}$ Department of Architecture and Built Environment, University of Nottingham, University Park, NG7 2RD, UK
}

\section{A R T I C L E I N F O}

\section{Article history:}

Received 26 November 2018

Received in revised form 27 March 2019

Accepted 17 April 2019

Available online $\mathrm{xxx}$

Keywords:

Dual-source heat pump (DSHP)

Flat-panel horizontal ground heat exchanger (HGHE)

Performance

Switching strategies

Sizing guidelines

\begin{abstract}
A B S T R A C T
Ground-coupled and air-source heat pumps (GCHPs and ASHPs, respectively) are regarded as energy efficient systems for air conditioning. Their coupling in a dual air and ground source heat pump (DSHP) can offer a further performance improvement by reducing the drawbacks of each standalone technology. In the present study, a DSHP coupled with a Flat-Panel as a horizontal ground heat exchanger (HGHE) is numerically analysed in comparison with its counterparts GCHP and ASHP, by implementing COMSOL Multiphysics to simulate heat transfer in the ground operated by the Flat-Panel. The DSHP operativity is provided by a function set to control the switching between air and ground sources, according to their temperatures and trigger thresholds. A parametric analysis has been then carried out in order to propose a preliminary guideline to size the Flat-Panel for a balance between energy saving and installation cost. The DSHP shows a higher efficiency in comparison with either ASHP or GCHP due to the switching between two sources to more favourable working temperatures, and can offer a profitable hybrid solution providing protection against frosting and size reduction of the HGHE, therefore helping to promote the penetration of heat pumps in the residential market.
\end{abstract}

(C) 2019 .

\section{Introduction}

The great opportunity for energy saving in buildings has been recognised globally. In view of this, the renewable energy technologies are spreading worldwide. Among them, air-source heat pumps (ASHPs) and ground-coupled heat pumps (GCHPs) are regarded as viable and efficient technologies for heating and cooling applications in residential and commercial buildings when the design is compliant with local environmental conditions [1-4].

The performance of a heat pump strictly depends on the operating conditions, according to the heating/cooling demand and the thermal source temperature. ASHPs have a low initial installation cost and are almost readily applicable even if their efficiency is potentially affected by the daily and the seasonal temperature variations. Moreover, these systems are subjected to frosting on the outdoor evaporator during the heating season in cold and humid conditions. Consequently, a reduction in efficiency and heating capacity could occur for ASHPs, thus defrost cycles are required to remove the frost and improve the performance [5]. If defrosting is obtained by inverting the refrigerant cycle, the coefficient of performance (COP) for the whole heating season can be reduced by up to $12.6 \%$, under certain conditions of relative humidity and outdoor air temperature [6,7]. Many techniques have been investigated to efficiently reduce the frequency of defrosting cycle or entirely avoid frosting on the outdoor unit of an ASHP $[8,9]$.

\footnotetext{
* Corresponding author.

Email address: michele.bottarelli@unife.it (M. Bottarelli)
}

In GCHPs systems, ground heat exchangers (GHEs) are used to thermally couple a heat pump with the ground (used as heat source/ sink), which often provides more favourable and stable temperature than outdoor air temperature. As a consequence, higher efficiency is expected for GCHP in comparison with the more widespread ASHPs [10]. However, GCHPs have higher purchase and installation cost than ASHPs, due to the additional cost for GHEs [6], which can be installed in vertical boreholes or shallow diggings (also referred as VGHEs and HGHEs, respectively) [11]. A GCHP coupled with VGHEs benefits from the relatively stable temperature in the deep ground and use geothermal energy from the earth [12]. On the other hand, a GCHP coupled with HGHEs uses the seasonal heat storage in the shallow soil so that its performance is affected by the climatic conditions, due to the low installation depth of the HGHEs. The HGHEs hold some advantages regarding costs and ease of installation but also drawbacks regarding land area requirements [13-15]. Towards a reduction in the size and costs of the ground coupling, recent research efforts have attempted to develop more efficient HGHE, such as the novel Flat-Panel, which has been developed at the University of Ferrara in $2012[13,16,17]$.

Given this, incorporating both the ground-source and the air-source in a dual-source heat pump (DSHP) could offer the opportunity to significantly reduce the size of the ground heat exchanger by adding a supplemental heat extraction or rejection subsystem to conventional GCHPs [18-24]. Moreover, an optimised DSHP can achieve high efficiency $[25,26]$ by switching to the more favourable source/sink between the air and ground according to their temperature, thus also preventing from frosting during winter for the outdoor 
air unit. Therefore, the DSHP could offer a profitable and viable solution for heating and cooling systems in market, combining the advantages of both ASHPs and GCHPs.

This study aims to analyse the behaviour of a DSHP coupled with a Flat-Panel HGHE and its potential benefits over conventional GCHPs. It is a follow-on step of our recent field trial and modelling studies on the Flat-panel HGHE and its connection with GCHP [13,16,17,26-28]. As shown in Fig. 1, a supplementary finned tube air-source heat exchanger is in a parallel connection with a Flat-Panel HGHE. At their inlet and out, there are solenoid valves to switch on or off flow. In COMSOL modelling of DSHP, a user-defined function has been programmed to realise a virtual control of switching between the air and ground heat exchangers according to the source temperatures and trigger thresholds. In such way, a building heating demand time series can be applied to the Flat-panel HGHE or the air-source heat exchanger of a DSHP. A parametric analysis has been carried out in order to determine a preliminary guideline to balance between the efficiency of a DSHP and the size reduction of the Flat-Panel HGHE.

\section{Methods}

The benefits of using a dual-source heat pump (DSHP) is evaluated numerically, in comparison to its counterpart water-to-water GCHP, which is taken as the reference case. The study is then extended to analyse the energy performance and preliminary operating guidelines of a DSHP. In this case, a conventional finned tube air heat exchanger is intended to be used as an additional heat extraction or as an alternative to the ground heat exchanger, according to the ambient air temperature. The ground coupling for both the GCHP and the DSHP consists of an innovative HGHE, named as Flat-Panel, which has been developed at the University of Ferrara. A detailed description of Flat-Panel HGHE and its high performance is reported previously in Refs. [16,26,28], particularly about the matching between experimental tests and modelling approach in COMSOL, and also standard regulation for GHEs sizing. The mean deviation between the experiment and COMSOL modelling is less than $1{ }^{\circ} \mathrm{C}$, on average. The validated modelling approach has therefore provided a basis for sizing and optimization of Flat-Panel HGHE and evaluation of its coupling with GCHP.

To calculate the energy demand, the building of the TekneHub laboratory of the University of Ferrara (TekneHub in following) was preliminarily simulated by means of the EnergyPlus (E+) software. Then, the specific heating requirement time series is used as the ground heat load in a 2D numerical model of the HGHE, which was implemented in the numerical code COMSOL Multiphysics [27]. The Flat-Panel HGHE model is used to simulate the heat transfer in the ground, to evaluate the temperature trend of the ground source in the GCHP and the DSHP. In the DSHP numerical model, a function has been set to control the switching between the air and ground sources, according to a minimum temperature threshold for the outdoor air and the ground, and the temperature difference between them. Finally, a parametric analysis of ground heat load at the HGHE is performed to evaluate the opportunity to reduce the length of the HGHE with a DSHP maintaining a good efficiency in comparison to the sole GCHP and ASHP systems.

\subsection{Heating energy demand}

In order to estimate the heating load, the well-known building energy simulation software EnergyPlus was used to simulate the TekneHub laboratory, as reference case [27]. The accuracy of EnergyPlus simulation has been verified by many researchers [29], so it has been well accepted worldwide. The TekneHub laboratory takes part to the High Technology Network of Emilia-Romagna region, and is located in the city of Ferrara $\left(44^{\circ} 50^{\prime} \mathrm{N} 11^{\circ} 37^{\prime} \mathrm{E}\right)$, in northern Italy. The local climate is humid continental climate, with a harsh and humid winter (2326 heating degree days). The building has only one floor with a gross floor area of $880 \mathrm{~m}^{2}$ and a gross volume of $3488 \mathrm{~m}^{3}$, subdivided into twenty rooms, as shown in Fig. 2.

The building envelope has been modelled in $3 \mathrm{D}$, as shown in Fig. 2, by means of OpenStudio, which is a plug-in to the software SketchUp. According to recent Italian regulations on the energy performance of building the building envelope is well insulated. The heating and cooling system of TekneHub consists of two air-to-air rooftop heat pumps with a capacity of $40 \mathrm{~kW}$ each. In the EnergyPlus model, the heat pumps system are set to operate continuously during the heating season. A comprehensive local weather dataset collected for year 2015 with the weather station operating at the TekneHub (Davis Vantage Pro 2) was imported in EnergyPlus in order to run a yearly simulation. The EnergyPlus simulation has been run for the whole year weather dataset, starting from October according to the Italian regulations for the beginning of heating season. In Fig. 3, the resulting hourly time series $Q_{t}$ of the overall building heating load (kW) is depicted together with the cumulative energy demand $h$ per building volume $\left(\mathrm{kWh} / \mathrm{m}^{3}\right)$. As detailed in section 2.3.1, the time series $Q_{t}$ is used to calculate the heating demand $q_{t}$ per building volume
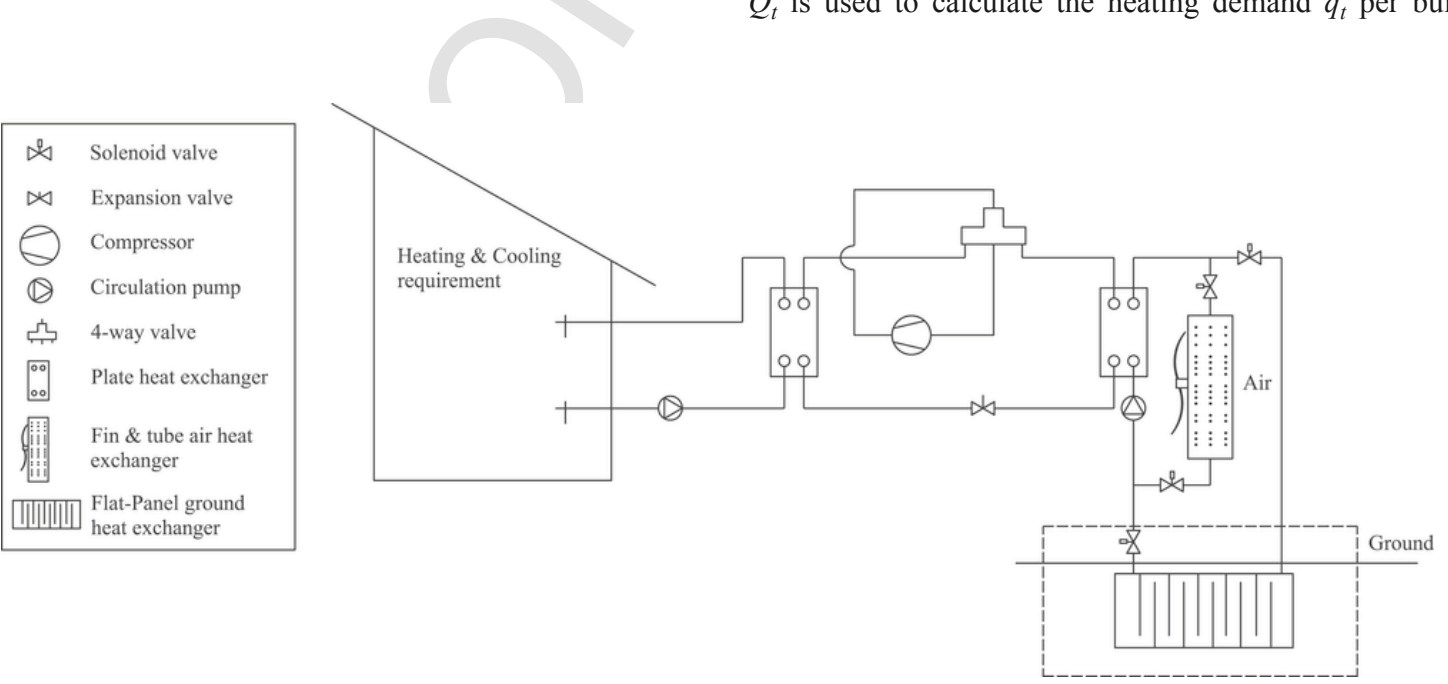

Fig. 1. Layout of the DSHP system coupled with a Flat-Panel HGHE. 

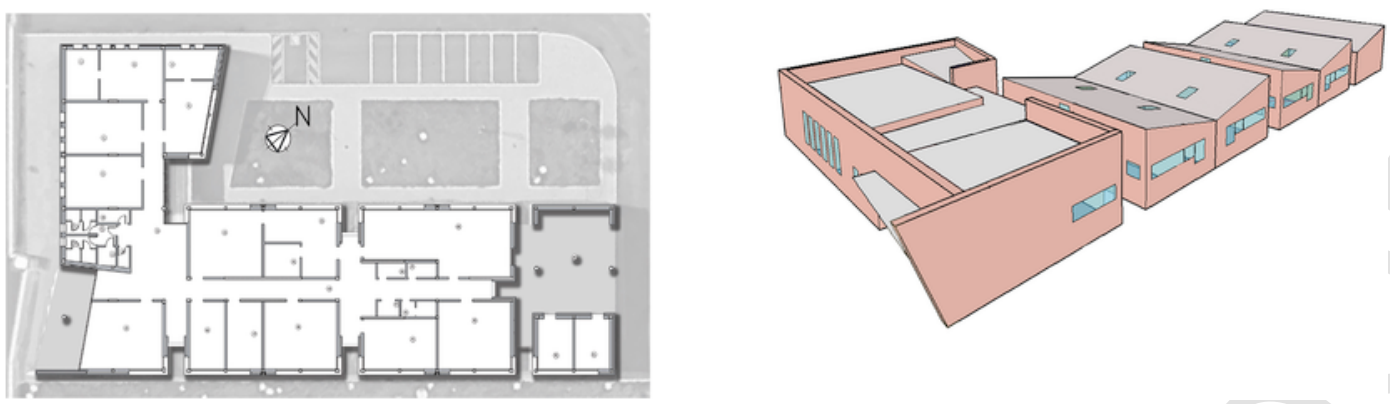

Fig. 2. The TekneHub building plan and its 3D model implemented in EnergyPlus.

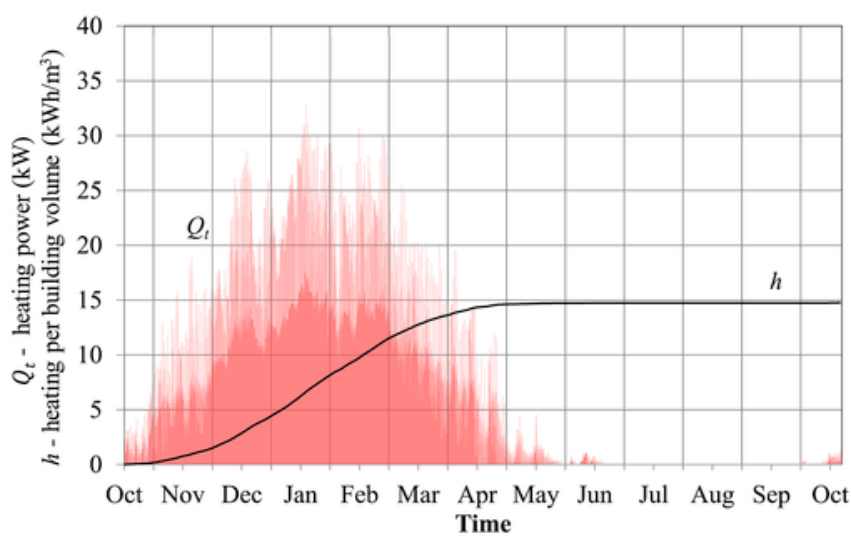

Fig. 3. Heating power $\left(Q_{t}\right)$ and heating demand per building volume $(h)$ for TekneHub.

$\left(\mathrm{W} / \mathrm{m}^{3}\right)$ and then to determine the heat flux $q_{g}$ at Flat-Panel HGHE in the numerical model of both GCHP and DSHP $\left(\mathrm{W} / \mathrm{m}^{2}\right)$. The winter energy demand $h$ per building volume accounts $15 \mathrm{kWh} / \mathrm{m}^{3}$, which classifies the envelope in energy class " $\mathrm{B}$ " of the Italian regulation.

Further details on the components of the building and on the energy demand calculation are not included in the present manuscript for the sake of brevity and can be found in Ref. [27].

\subsection{Efficiency estimation of heat pump}

For a heat pump, the coefficient of performance (COP) depends mainly on the temperature difference between condenser and evaporator, which is strictly related to the heat source temperatures. In the GCHP case, the evaporation temperature is related to the temperature of the working fluid coming from the Flat-Panel HGHE, whereas for DSHP this depends on the temperature of the air or ground when either is used.

In order to estimate and compare the performance achievable by GCHP and DSHP, we assumed a reference temperature of $48^{\circ} \mathrm{C}$ at the condenser. According to a given condensation temperature, neglecting superheating and subcooling conditions and considering the efficiency of the compressor and condenser, the thermodynamic cycle only depends on the temperature at the evaporator, for given refrigerant. This methodology is reported in Ref. [17] and is here used to calculate the COP with R134a as refrigerant, according to the heat transfer at the condenser. However, to more strictly link the COP with the source temperature, unlike the constant value considered in Ref. [17], we assume an isentropic efficiency of the scroll compressor to be variable according to the compression ratio, as shown in Fig. 4. The fitting curve in Fig. 4 follows the most optimistic efficiencies reported in literature, e.g. in Refs. [30-32], in order to comply the technology efforts for reducing scroll leakage losses. The COP here then

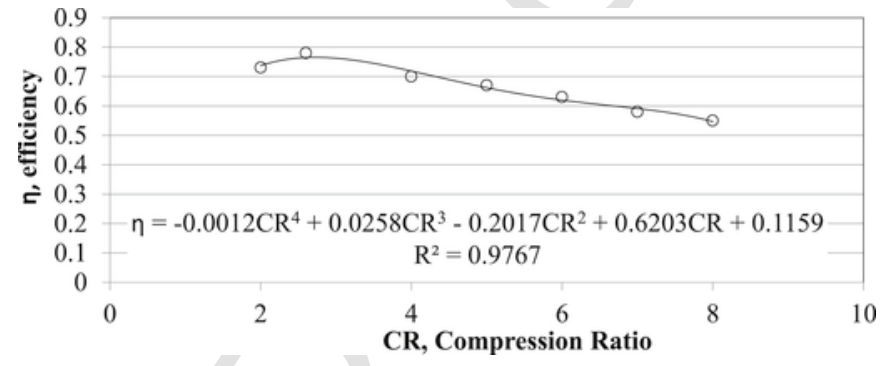

Fig. 4. Relationship between compressor efficiency and evaporation temperature.

used is calculated by multiplying the COP resulting from the methodology reported in Ref. [17] by the fitting curve depicted in Fig. 4, according to the relationship between evaporation temperature and pressure for R134a refrigerant.

According to all former simplifications, the COP becomes a function of the evaporation temperature, as shown in Fig. 5, which is assumed to be equal to the temperature of the source (air, ground) in the following, for simplicity. Therefore, from this formula, the electricity consumption can be calculated for given heating power and evaporation temperature.

\subsection{Numerical modelling}

The numerical analysis was conducted via COMSOL Multiphysics, solving the heat transfer problem in solids in order to calculate the variation in the temperature distribution of the ground source, due to heat extraction by a Flat-Panel HGHE in coupling with a GCHP or a DSHP. The problem is numerically described by the following Eq. (1) and solved via finite element method [33]:

$\rho C_{p} \frac{\partial \mathrm{T}}{\partial \mathrm{t}}=\nabla(\mathrm{k} \nabla \mathrm{T})+\mathrm{Q}$

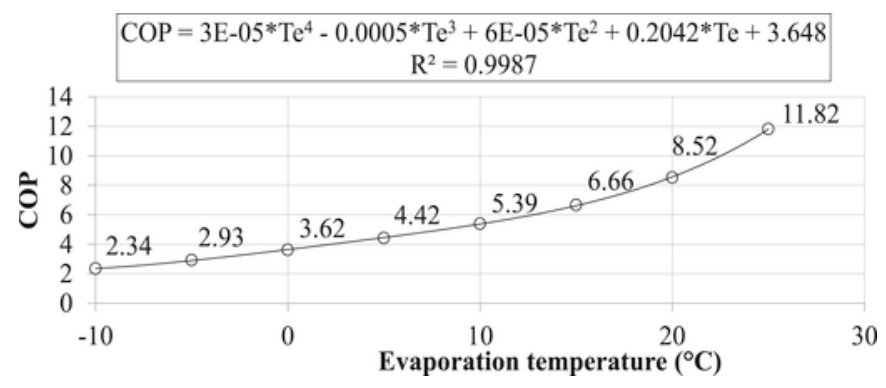

Fig. 5. Relationship between COP and evaporation temperature. 
where:

- $\rho$ is the solid density, $\mathrm{kg} / \mathrm{m}^{3}$;

- $C_{p}$ is the solid heat capacity at constant pressure, $\mathrm{J} /(\mathrm{kg} \cdot \mathrm{K})$;

- $k$ is the solid thermal conductivity, $\mathrm{W} /(\mathrm{m} \cdot \mathrm{K})$;

- $Q$ is the heat source/sink, $\mathrm{W} / \mathrm{m}^{3}$.

The 2D computational domain consists of a Flat-Panel HGHE cross-section and a large surrounding soil part $(6 \mathrm{~m}$ wide and $10 \mathrm{~m}$ deep), as shown in Fig. 6. Two Flat-Panels are spaced by $3.0 \mathrm{~m}$ and laid to a depth of $2.5 \mathrm{~m}$. Each Flat-Panel is $1.5 \mathrm{~m}$ high, so its two sides have a total heat transfer surface of $3 \mathrm{~m}^{2}$ per meter trench length. In the 2D model domain, the Flat-Panel is represented with a heat flux boundary condition. According to this approach, the Flat-Panel shape is simplified to a cold/hot plate, to and from which heat transfer from the surrounding soil by heat conduction. A $2 \mathrm{D}$ model can be considered as the representative of a three-dimensional geometry in the hypothesis that the temperature change is small along the exchanger between its inlet and outlet and that no thermal stratification occurs within the working fluid [28]. In view of this, the average temperature at the interface between the Flat-Panel and the ground is representative of the average temperature of the working fluid.

The finite element grid resolution is higher near the Flat-Panel boundary where a higher temperature gradient exists, while it is lower in the outer domain. The full mesh consists of 11,200 elements. In order to check the grid independence, a preliminary analysis was carried out by increasing the number of the elements and the current grid resolution was found sufficient.

The soil is considered to be homogeneous with constant thermal properties, as reported in Table 1.

\subsubsection{Boundary conditions}

For the top and the bottom of the numerical domain, 1st kind boundary conditions were set: a time series of the hourly measured temperatures on the ground surface in 2015 and a constant temperature of $16.7^{\circ} \mathrm{C}$ at the bottom, which is equal to the yearly average

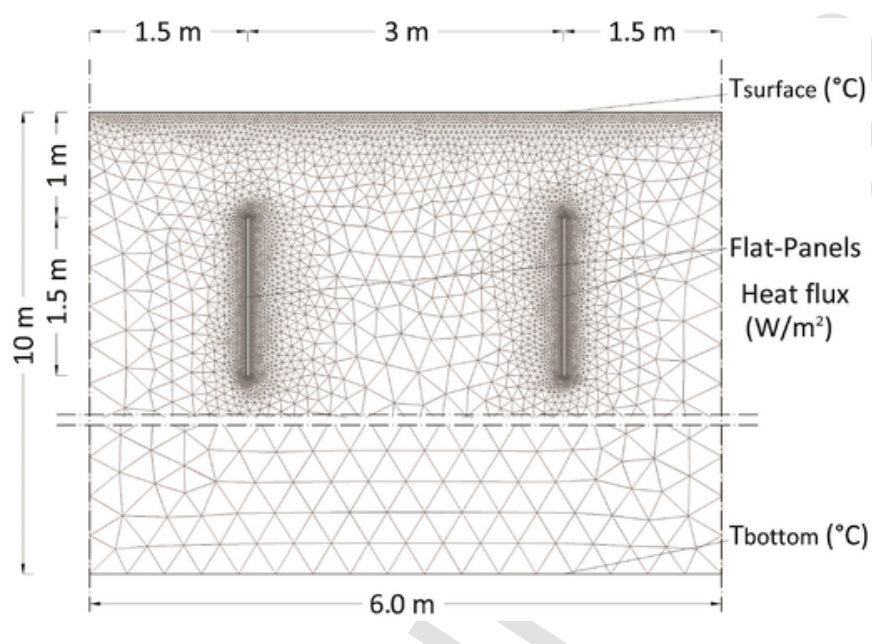

Fig. 6. Sketch of the 2D model domain, boundary conditions and mesh.

Table 1

Physical properties of soil [27].

\begin{tabular}{ll}
\hline Thermal conductivity, $k$ & $0.8 \mathrm{~W} / \mathrm{m} \cdot \mathrm{K}$ \\
\hline Density, $\rho$ & $1600 \mathrm{~kg} / \mathrm{m}^{3}$ \\
Specific heat, $C_{p}$ & $1500 \mathrm{~J} / \mathrm{kg} \cdot \mathrm{K}$ \\
\hline
\end{tabular}

ground temperature at shallow depth, respectively. An adiabatic condition is assigned to the side boundaries. The reliability of setting a 1st kind boundary condition at the ground surface unlike a full energy balance (3rd kind) is compliant with the results reported in Ref. [13], in which it is clearly show that no temperature differences are detectable beyond $0.8 \mathrm{~m}$ deep.

According to Ref. [27], the Flat-Panels are simplified as a boundary heat source (2nd kind boundary condition). The heat flux $q_{g}$ (W/ $\mathrm{m}^{2}$ ) is calculated at hourly scale using Eq. (2), according to all approximations proposed in Ref. [27]:

$$
q_{g}(\mathrm{t})=\frac{\mathrm{r} \cdot q_{t}}{\mathrm{~S}_{F P}}
$$

where:

- $q_{t}$ is the heating load per unit volume of building space, as calculated at hourly scale by means of the EnergyPlus, $\mathrm{W} / \mathrm{m}^{3}$;

- $S_{F P}$ is the heat transfer surface per meter length of a Flat-Panel $\mathrm{HGHE}, \mathrm{m}^{2} / \mathrm{m}$;

- $r$ is the volume-to-length ratio between the building space volume $\left(\mathrm{m}^{3}\right)$ and the length of Flat-Panel $(\mathrm{m}), \mathrm{m}^{3} / \mathrm{m}$.

According to Eq. (2), the heat flux $q_{g}\left(\mathrm{~W} / \mathrm{m}^{2}\right)$ at the Flat-Panel is directly related to the heat load per meter length $r \cdot q_{t}(\mathrm{~W} / \mathrm{m})$, and the surface area per meter length, which is $3 \mathrm{~m}^{2} / \mathrm{m}$ for a $1.5 \mathrm{~m}$ high Flat-Panel. Introducing the volume-to-length ratio $r$ is a unique way to link the required length of Flat-Panel with a building heating demand $q_{t}\left(\mathrm{~W} / \mathrm{m}^{3}\right)$. For example, if the volume-to-length ratio $r$ is to be set as 5 , there would be a maximum value of $r \cdot q_{t}=45.9 \mathrm{~W} / \mathrm{m}$ for the hourly time series of heating demand given by EnergyPlus simulation of TekneHub building. In the following parametric comparison, $r$ is varied around 5 .

\subsubsection{Virtual control of boundary condition at Flat-Panel}

In the DSHP case, the heat flux at the Flat-Panel is controlled by a user-defined function which has been programmed in the model, thus simulating the switching between air and ground sources for the DSHP. The flowchart of the operating rules for the DSHP is reported in Fig. 7. As a consequence, the heat flux $q_{g}$ at the Flat-Panel is zero when the DSHP is switched to the air source only, i.e., in the mode of ASHP, otherwise, it is negative in the mode of GCHP with use of ground source only.

The ground allows better working conditions when its temperature is higher than that of the outdoor air in winter. In the model, the ground source is used when the outdoor air temperature is below $5^{\circ} \mathrm{C}$ ( $T_{\text {air lim }}=5^{\circ} \mathrm{C}$ ), thus avoiding most of the frosting conditions in cold and harsh climates $[5,6]$. Furthermore, the function performs a control of the ground source temperature $T_{g}$ at each time step, and activates the boundary heat source (i.e., Flat-Panel) only if $T_{g}$ is still higher than the outdoor air temperature by an onset temperature differential, $D T$. Finally, an operating threshold is set for the ground source temperature $\left(T_{g} \lim =-2{ }^{\circ} \mathrm{C}\right)$, to avoid the frosting of the working fluid within the Flat-Panel. Otherwise, in all other conditions, the boundary heat source term is set to zero, thus simulating the operation of the DSHP using the air source only.

The temperature of the air source is defined through the outdoor air temperature time series of the year 2015, implemented in the model at an hourly average time scale. The temperature of the ground source is calculated by the model at each time step and here reported at hourly scale as the average temperature at the Flat-Panel boundary. Both GCHP and DSHP models were run for a simulation period of one year, starting from the middle of October, and storing results at 


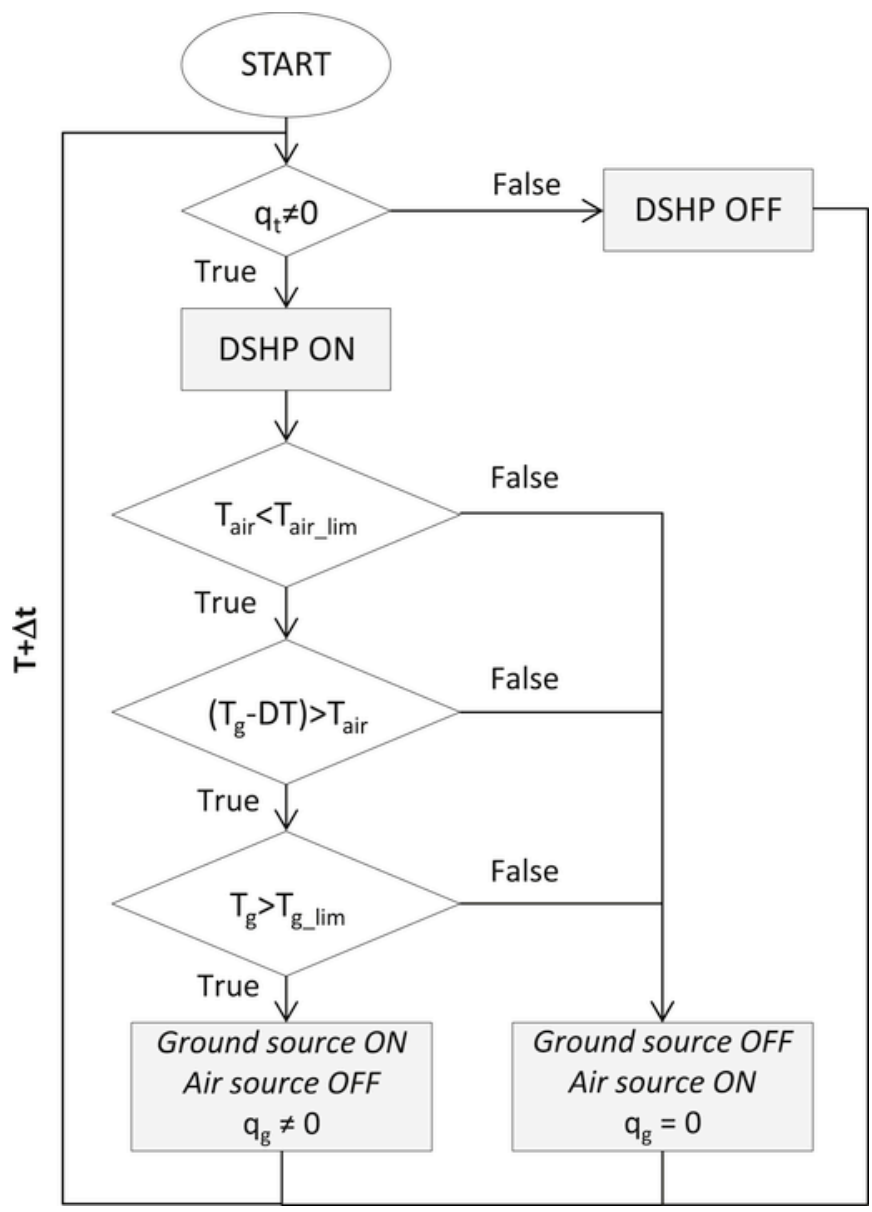

Fig. 7. Operating flowchart of the DSHP routine.

hourly steps. In the DSHP case, the user function routine was called for each time step.

The initial temperature distribution in the soil domain was derived from experimental measurements of soil temperature at various depths.

\subsubsection{Parametric analysis}

A DSHP uses the ground as the heat source depending on the operating rules, because a conventional outdoor air unit is intended to be exploited for alternative heat extraction or rejection. According to this rule, the size of the ground heat exchanger could be significantly reduced compared to a GCHP $[20,26]$, with a significant saving regarding of cost of installation. Given this, a detailed parametric analysis of the heat load at the Flat-Panel has been performed, thus simulating different lengths of Flat-Panel. Five values of the parameter $r$, besides the reference volume-to-length ratio $r=5 \mathrm{~m}^{3} / \mathrm{m}\left(5 \mathrm{~m}^{3}\right.$ of building space are supplied with each meter of Flat-Panel), were assumed: 7.5, 10, 15, 20,30 , corresponding to a Flat-Panel length reduction of $33 \%, 50 \%$, $67 \%, 75 \%$ and $83 \%$, respectively.

To investigate the heat pump operating rules, the parametric analysis is also extended to seven values for the onset temperature differential ( $D T=0,1,2,3,5,7$, and $10 \mathrm{~K}$, respectively). The higher is $D T$, the lower is the possible operating time for the DSHP exploiting the ground source. On the other hand, this preserves the ground source, so that even more favourable working condition can be achieved in comparison with the air source.
Overall, a total of 43 cases have been simulated: 1 for GCHP and 42 (6 volume-to-length ratio $r$ values and 7 onset temperature differential $D T$ values) for the DSHP models.

\section{Results and discussion}

The Flat-Panel HGHE model was simulated in coupling with a GCHP and DSHP, respectively, for a simulation period of one year. The GCHP case $\left(r=5 \mathrm{~m}^{3} / \mathrm{m}\right)$ is taken as the reference for comparison with the DSHP solution in terms of thermal source temperature and system efficiency. A parametric analysis of the same Flat-Panel in conjunction with a DSHP was performed, under the same boundary conditions, for various values of the volume-to-length ratio $r(5,7.5$, $\left.10,15,20,30 \mathrm{~m}^{3} / \mathrm{m}\right)$ and onset temperature differential $D T(0,1,2,3$, $5,7,10 \mathrm{~K})$, to evaluate the virtual design and operation of DSHP.

\subsection{Comparison between reference case GCHP and base case $D S H P^{*}\left(r=5 \mathrm{~m}^{3} / \mathrm{m} ; D T=0 K\right)$}

The hourly temperature of the ground source $T_{g}$ is shown in Fig. 8 for the reference case GCHP, during the heating season from mid-October to mid-April (180 d), as the average temperature calculated at the interface between the Flat-Panel and the ground. The ground source temperature is compared with the outdoor air temperature $T_{\text {air }}$ (following a precautionary approach, this is assumed to be representative of the air temperature at the outdoor unit of an ASHP) and with the undisturbed ground temperature at the average depth of the Flat-Panel $(-1.75 \mathrm{~m})$

According to the simplifications adopted, the temperature $T_{g}$ decreases to a minimum of $1.9^{\circ} \mathrm{C}$, around the end of February. The Flat-Panel proves adequate to meet the winter heating requirement: a total of $73.8 \mathrm{kWh} / \mathrm{m}$ and $5205 \mathrm{~h}$ of operating time, corresponding to a seasonal average heat extraction power of $14 \mathrm{~W} / \mathrm{m}$ per unit Flat-Panel length (maximum $45.9 \mathrm{~W} / \mathrm{m}$ ) in continuous operation. According to air and ground source temperatures, the reference case GCHP can achieve a better efficiency than the reference case ASHP for the first 100 days. Starting from February, $T_{g}$ is still profitable during night-time and cold days. However, when the average $T_{g}$ become lower than $T_{\text {air }}$ and it would be therefore less favourable in late winter. Moreover, in the beginning and near the end of the heating season, the air temperature rarely decreases below $5^{\circ} \mathrm{C}\left(T_{\text {air lim }}\right)$, so that the frosting at the outdoor air unit is not expected according to the low heat load.

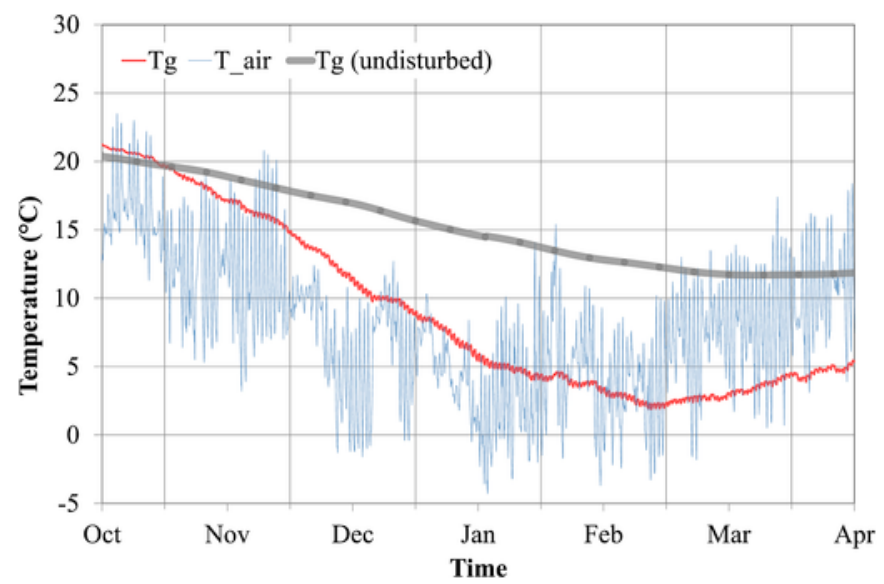

Fig. 8. Temperatures of $T_{\text {air }}$, undisturbed ground and Flat-Panel surface in the reference case GCHP. 
Fig. 9 shows a frequency histogram of the hourly difference between the outdoor air temperature and the calculated average surface temperature of Flat-Panel in the ground, when the GCHP is operating. The temperature difference data of the yearly simulation are grouped for an interval of $2 \mathrm{~K}$. The total operating hours for each group of temperature difference and the cumulative percentage frequency are also reported. The temperature difference between the sources varies in relation to the daily and seasonal variation in $T_{\text {air }}$. The accumulative percentage frequency shows that the ground source offer a favourable working condition $\left(T_{\text {air }}-T_{g} \leq 0\right)$ for just over half of the GCHP operating time $(5205 \mathrm{~h})$, in comparison with the air source.

In view of this, a DSHP using the more favourable condition between the air and ground source could be an efficient solution. This potential in energy efficiency was initially evaluated assuming the same Flat-Panel size as in the reference case GCHP $\left(r=5 \mathrm{~m}^{3} / \mathrm{m}\right)$, and simplifying the function with a setting $D T=0 \mathrm{~K}$ for controlling the switching between the two thermal sources, which means that the Flat-Panel is used by the DSHP when the temperature of the ground source is higher than the air temperature (base case DSHP*). Heat extracted from the ground source decreases to $29.7 \mathrm{kWh} / \mathrm{m}, 40 \%$ of the total heat extraction required, due to the reduced operating time of the Flat-Panel (1246 h out of $5205 \mathrm{~h}$ ), to which corresponds a higher average heat extraction power of $23.8 \mathrm{~W} / \mathrm{m}$. The frequency histogram of the hourly difference of ground source temperatures between the base case DSHP* and reference case GCHP with the same $r=5 \mathrm{~m}^{3} / \mathrm{m}$ is shown in Fig. 10, similarly to Fig. 9. The base case DSHP* can have a more favourable ground condition for more than $70 \%$ of the total operating time in comparison with the reference case GCHP.

We calculated the COP of the base case DSHP* and the reference GCHP using the relationship reported in Fig. 5, according to the temperature of the air and the ground source. The ratio of COP between DSHP* and the GCHP is shown in Fig. 11. Moreover, the seasonal electricity savings for Flat-Panel length units has been estimated. As expected, the DSHP* achieve a better efficiency than the GCHP when the heating demand is high from January. This is due to the fact DSHP* can allow a lower heat extraction from the ground. In the later heating season, the benefit by DSHP* can be more when the outdoor air temperature increases. For a heating period of 180 days, the electricity saving by DSHP* is estimated to be $1.12 \mathrm{kWh} / \mathrm{m}$ per meter length of Flat-Panel.

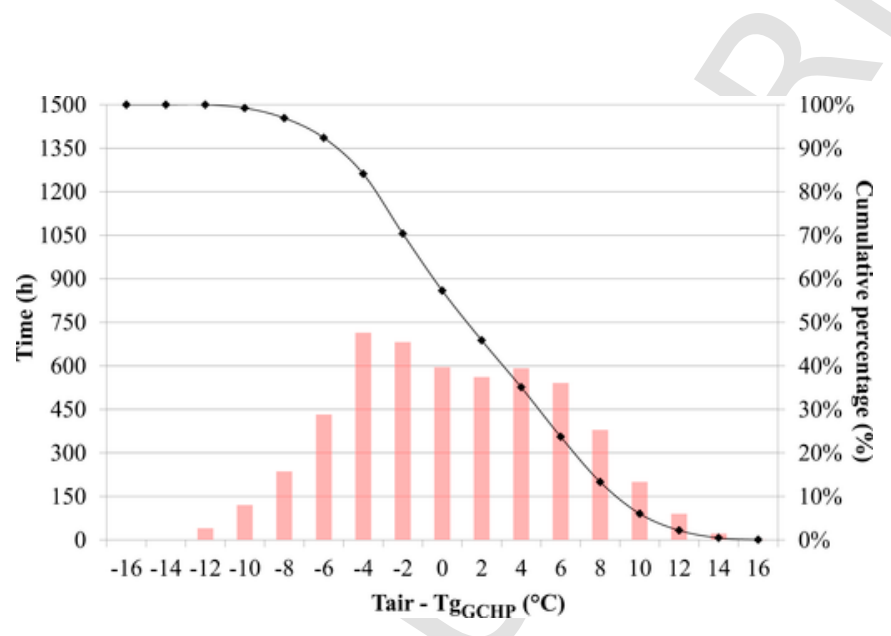

Fig. 9. The summed hours and cumulative frequency for the whole range of temperature difference between air and ground sources in the reference case GCHP.

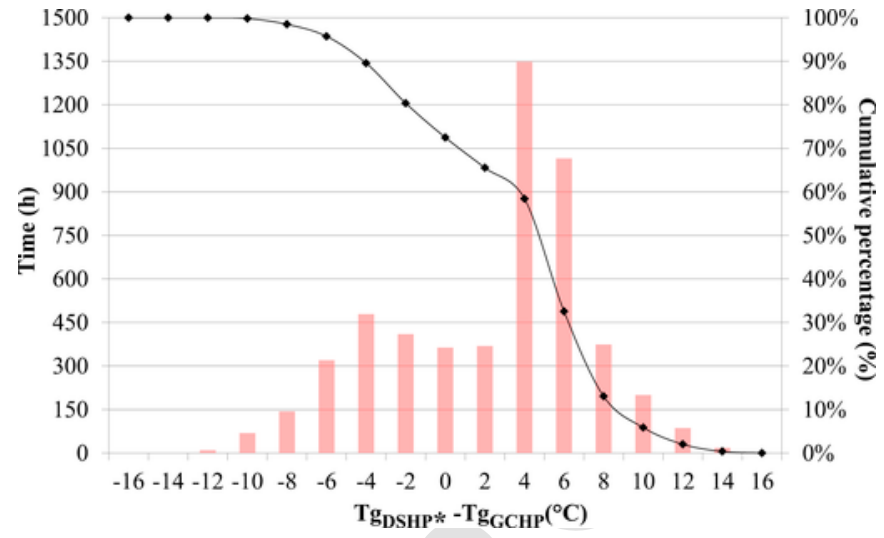

Fig. 10. The summed hours and cumulative frequency for the whole range of the ground source temperature difference at $2{ }^{\circ} \mathrm{C}$ interval between the base case DSHP and reference case GCHP.

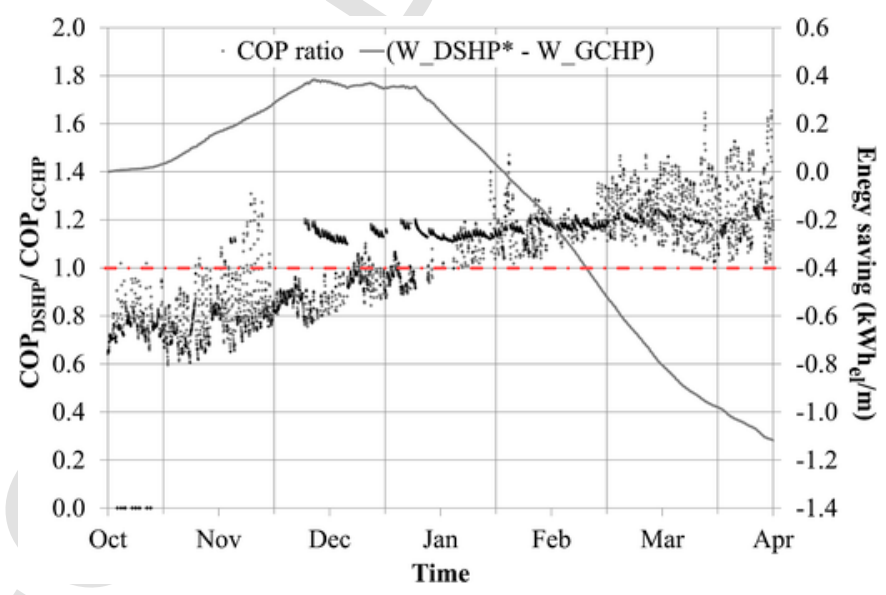

Fig. 11. Performance comparison between DSHP* and GCHP.

\subsection{Effect of reducing $r$ value and varying $D T$}

However, the DSHP solution could also offer the possibility of reducing the size of the Flat-Panel HGHE and consequently a significant saving on the installation cost, as well as on operating cost according to the more favourable condition defined in the operating rules.

For various values of parameters $r$ and $D T$, the annual heat extraction from the ground and the average heat extraction power on the Flat-Panel surface are shown in Fig. 12 on the basis of per unit length of Flat-Panel. As the volume-to-length ratio $r\left(\mathrm{~m}^{3} / \mathrm{m}\right)$ increases (i.e. less length of Flat-Panel per $\mathrm{m}^{3}$ building space), the average heat extraction power increases significantly.

Likewise, the energy extracted from the ground decreases as the onset temperature difference $D T$ increases, which can give more thermal preservation for the ground. In the case $r=30$, which is equivalent to about $17 \%$ of the Flat-Panel length at the reference $r=5$, the ground heat extraction per meter of Flat-Panel is around 78 and $33 \mathrm{kWh} / \mathrm{m}$ for the onset temperature differential $D T=0 \mathrm{~K}$ and $D T=10 \mathrm{~K}$, respectively, while the average heat extraction power 130 and $150 \mathrm{~W} / \mathrm{m}$.

According to the effect of parameters $r$ and $D T$ on ground heat extraction, the operating time of the Flat-Panel would decrease when $r$ and/or $D T$ increase, as shown in Fig. 13, which also gives the nor- 


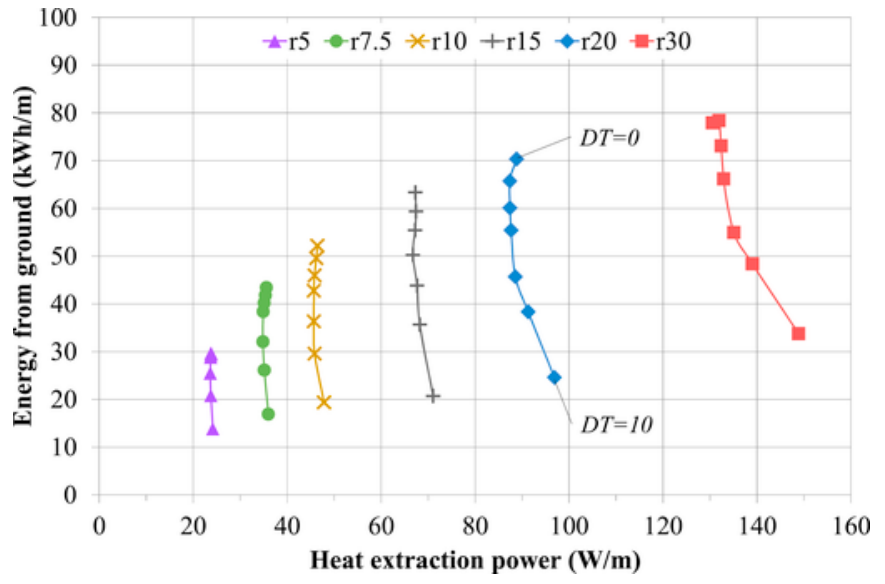

Fig. 12. Relation between the total ground heat extraction and the average heat extraction power on at the Flat-Panel.

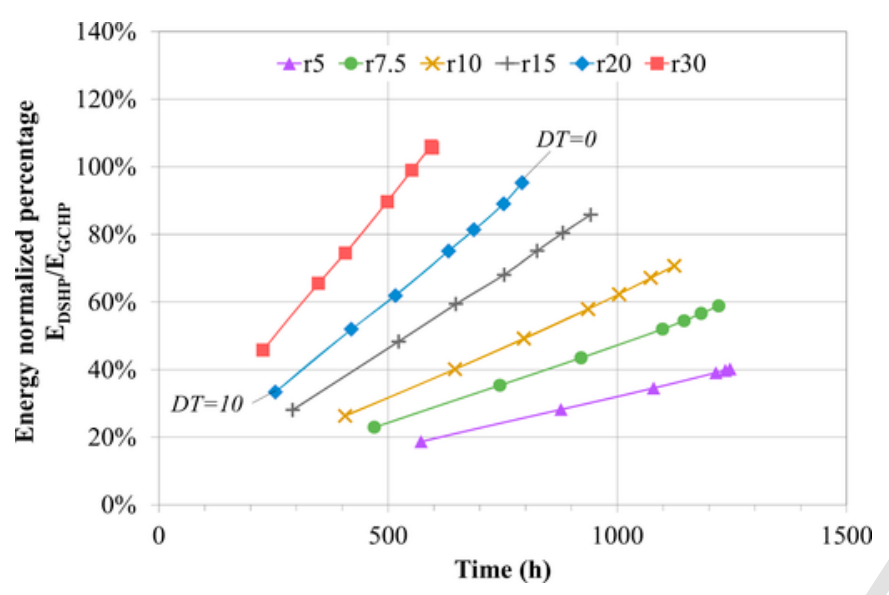

Fig. 13. Operating time and normalised ground heat extraction for various values of volume-to-length ratio $r\left(\mathrm{~m}^{3} / \mathrm{m}\right)$ and onset DT $\left({ }^{\circ} \mathrm{C}\right)$.

malised ground heat extraction with reference to the reference case GCHP. An approximate linear relationship can be seen between the operating time and normalised ground heat extraction.

The use of the ground source is controlled and limited by the operating rules as described earlier. Fig. 14 shows the minimum average surface temperature $T_{g}$ seasonally reached from the Flat Panel HGHE. The values are above $0{ }^{\circ} \mathrm{C}\left(T_{g}>0{ }^{\circ} \mathrm{C}\right)$ when the volume-to-length ratio $r$ is lower than 10 (the minimum $T_{g}$ for the reference case GCHP is $1.9^{\circ} \mathrm{C}$ ). For the volume-to-length ratio $r$ higher than $10, T_{g}$ may decrease below $0^{\circ} \mathrm{C}$ and reach the threshold temperature setting $-2{ }^{\circ} \mathrm{C}$, as controlled by the operating rules.

\subsection{Energy saving and preliminary sizing rules of HGHE Flat-Panel}

As carried out for the comparison between the COP of the base case DSHP* and the reference GCHP using the relationship reported in Fig. 5, we calculates the electricity saving or increase of DSHP in comparison with GCHP for each case, with exclusion of electricity used for defrosting. The results are shown in Table 2, in which $L_{\text {ratio }}$ is the ratio of Flat-Panel length with reference to the base case $\left(r=5 \mathrm{~m}^{3} / \mathrm{m}\right)$. Some cases of DSHP as shaded in Table 2 are profitable in comparison with the reference case GCHP because they would have less electricity demand for the same Flat-Panel length or they can allow a reduction of the Flat-Panel length by up to $70 \%$ for the

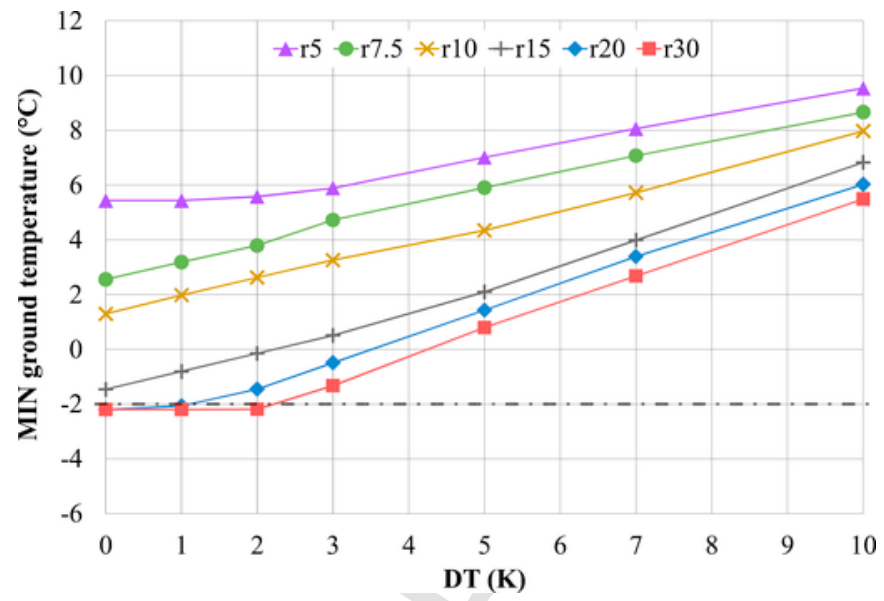

Fig. 14. Minimum average surface temperature of the Flat-Panel in the ground during heating season.

Table 2

Decrease (saving) or increase in electricity demand $(\mathrm{kWh} / \mathrm{m})$ of DSHP over the reference case GCHP on the basis of same heating demand.

\begin{tabular}{c|c|ccccccc}
\hline $\begin{array}{c}\text { volume-to-length ratio, } \begin{array}{c}L_{\text {ratio }} \\
\left(\mathrm{m}^{3} / \mathrm{m}\right)\end{array} \\
(-)\end{array}$ & \multicolumn{7}{|c}{$\begin{array}{c}\text { Onset } D T \\
\left({ }^{\circ} \mathrm{C}\right)\end{array}$} \\
\hline & & 0 & 1 & 2 & 3 & 5 & 7 & 10 \\
\hline 5 & 1 & -1.12 & $-\mathbf{- 1 . 1 2}$ & -1.12 & -1.12 & -1.08 & -0.94 & -0.59 \\
7.5 & 0.67 & -0.64 & -0.67 & -0.71 & $\mathbf{- 0 . 7 5}$ & -0.72 & -0.63 & -0.32 \\
10 & 0.50 & -0.27 & -0.34 & -0.40 & -0.44 & $\mathbf{- 0 . 4 5}$ & -0.39 & -0.15 \\
15 & 0.33 & 0.17 & 0.06 & -0.03 & -0.07 & $\mathbf{- 0 . 1 4}$ & -0.10 & 0.14 \\
20 & 0.25 & 0.41 & 0.29 & 0.21 & 0.15 & 0.12 & $\mathbf{0 . 1 1}$ & 0.23 \\
30 & 0.13 & 0.65 & 0.53 & 0.43 & 0.37 & 0.30 & $\mathbf{0 . 2 6}$ & 0.29 \\
\hline
\end{tabular}

same electricity demand. Any further increase in volume-to-length ratio $r$ would lead to lower seasonal efficiency, which could be however well compromised by a reduction in the installation cost.

Taking into consideration the reduction in electricity demand (Table 2) and the operational limitation emerged for the DSHP (Fig. 14), it is possible to identify the maximum benefits achievable according to the operating rules $(D T)$ and to the size of the ground heat exchanger, as shown in Fig. 15, which indicates 6 cases as bolded in Table 2. Compared to the reference case GCHP, the DSHP solution

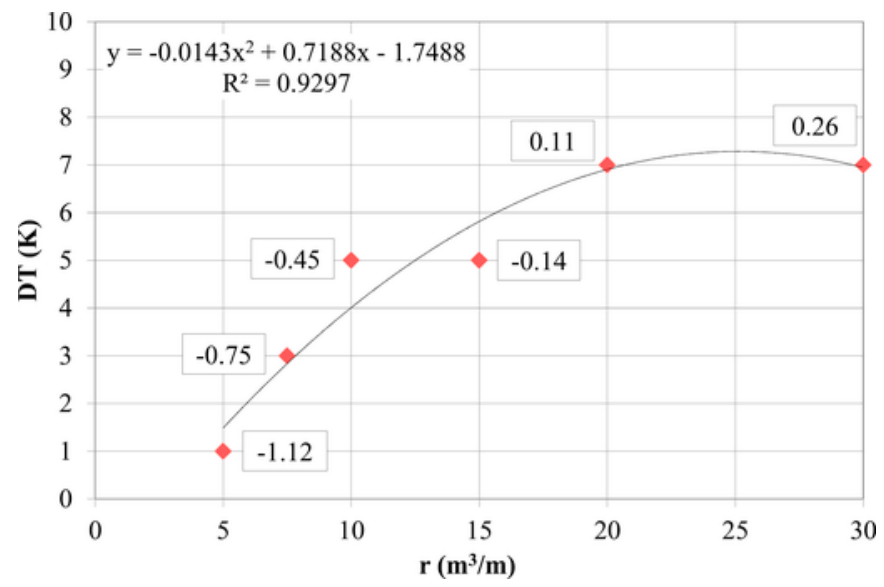

Fig. 15. Guidelines for the maximum DSHP benefits $(\mathrm{kWh} / \mathrm{m})$. 
offers the best combination of efficiency and opportunity to reduce the installation cost when the volume-to-length $r$ is between 10 and 15, which corresponds to a Flat-Panel to be $50 \%$ and $67 \%$ smaller than the reference case GCHP with $r=5 \mathrm{~m}^{3} / \mathrm{m}$.

Finally, it is possible to carry out a rough remark between the present study and what reported in Ref. [17] in terms of payback time for a full GCHP compared with a condensing boiler. In Ref. [17], the lower is the heating demand at HGHE Flat-Panels, the shorter is their length and therefore the payback time; especially for $r$ values around $3 \mathrm{~m}^{3} / \mathrm{m}$ (Table 9), the payback time is less than 5 years (Table 14). Therefore, a DSHP can be considered a profitable alternative also to traditional heating systems, commonly inexpensive in terms of installation costs, by having a short payback time.

\section{Conclusions}

This study has analysed the behaviour of a dual air and ground source heat pump (DSHP) coupled with a novel Flat-Panel HGHE (horizontal ground heat exchanger) and its potential benefits over conventional ground coupled heat pump (GCHP) in terms of higher efficiency and size reduction.

The commercial FEM code COMSOL Multiphysics has been used to evaluate the performance of DSHP in comparison to an equivalent GCHP. Both DSHP and GCHP have been modelled with a building heating load time series as a boundary condition of the Flat-Panel HGHE. In the DSHP case, the heat flux at the Flat-Panel is controlled by a programmed user-defined function to simulate the switching between air and ground thermal sources.

A parametric analysis has been carried out towards the identification of a preliminary design guideline to size the Flat-Panel HGHE for an optimal DSHP performance with a good balance between the efficiency and the Flat-Panel size.

The simulation results show that an air source heat exchanger can be a beneficial supplemental heat extraction or rejection unit and even an alternative to the ground heat exchanger when the air condition allows more favourable working conditions for the heat pump.

Moreover, the use of a DSHP can offer a significant size reduction of the Flat-Panel HGHE and therefore a lower installation cost, because an alternate use of air source can preserve ground thermal source and allow a smaller area of Flat-Panel working under a more beneficial condition. In view of this, the use of DSHP coupled with a high-efficiency Flat-Panel HGHE can offer an efficient and cost-effective heating solution.

\section{Nomenclature}

$\begin{array}{ll}\rho & \text { solid density }\left[\mathrm{kg} / \mathrm{m}^{3}\right] \\ k & \text { solid thermal conductivity }[\mathrm{W} /(\mathrm{m} \cdot \mathrm{K})] \\ D T & \text { temperature differential between air and ground }\left[{ }^{\circ} \mathrm{C}\right] \\ C O P & \text { coefficient of performance } \\ C_{p} & \text { solid heat capacity at constant pressure }[\mathrm{J} /(\mathrm{kg} \cdot \mathrm{K})] \\ Q & \text { heat source } / \text { sink within a solid }\left[\mathrm{W} / \mathrm{m}^{3}\right] \\ q_{g} & \text { heat flux at the HGHE }\left[\mathrm{W} / \mathrm{m}^{2}\right] \\ q_{t} & \text { heating demand per building volume }\left[\mathrm{W} / \mathrm{m}^{3}\right] \\ R & \text { the volume-to-length ratio between the } \mathrm{building} \text { vol- } \\ & \text { ume and the length of Flat-Panel HGHE }\left[\mathrm{m}^{3} / \mathrm{m}\right] \\ S_{F P} & \text { heat transfer surface of a Flat-Panel HGHE per unit } \\ & \text { length }\left[\mathrm{m}^{2} / \mathrm{m}\right] \\ T_{\text {air }} & \text { outdoor air temperature }\left[{ }^{\circ} \mathrm{C}\right] \\ T_{\text {air } l i m} & \text { temperature threshold for outdoor air temperature in } \\ & \text { winter }\left[{ }^{\circ} \mathrm{C}\right] \\ T_{g} & \text { ground source temperature }\left[{ }^{\circ} \mathrm{C}\right]\end{array}$

$T_{g_{-} \text {lim }}$ temperature threshold for ground temperature in winter $\left[{ }^{\circ} \mathrm{C}\right]$

\section{References}

[1] EC, Communication from the Commission to the European Parliament, the Council, the European Economic and Social Committee and the Committee of the Regions - an EU Strategy on Heating and Cooling, SWD 24 Final, 2016 https://ec.europa.eu/transparency/regdoc/rep/1/2016/EN/1-2016-51-EN-F1-1. PDF.

[2] L. Aresti, P. Christodoulides, G. Florides, A review of the design aspects of ground heat exchangers, Renew. Sustain. Energy Rev. 92 (2018) 757-773.

[3] V. Somogyi, V. Sebestyén, G. Nagy, Scientific achievements and regulation of shallow geothermal systems in six European countries - a review, Renew. Sustain. Energy Rev. 68 (2017) 934-952.

[4] A.D. Chiasson, Advances in Modeling of Ground-Source Heat Pump Systems, Master's Thesis Oklahoma State University, USA, 1999.

[5] F. Wang, C. Liang, X. Zhang, Research of anti-frosting technology in refrigeration and air conditioning fields: a review, Renew. Sustain. Energy Rev. 81 (2018) 707-722.

[6] P. Vocale, G.L. Morini, M. Spiga, Influence of outdoor air conditions on the air source heat pumps performance, Energy Proc. 45 (2014) 653-662.

[7] M. Dongellini, C. Naldia, G.L. Morini, Annual performances of reversible air source heat pumps for space conditioning, Energy Proc. 78 (2015) 1123-1128.

[8] F. Wang, G. Wang, Y. Zheng, Z. Lin, P. Hao, C. Huan, T. Wang, Performance investigation of a novel frost-free air-source heat pump water heater combined with energy storage and dehumidification, Appl. Energy 139 (2015) 212-219.

[9] Y.J. Jang, H.B. Bae, J.S. Lee, Y.M. Ha, Continuous heating of an air-source heat pump during defrosting and improvement of energy efficiency, Appl. Energy 110 (2013) 9-16.

[10] J.F. Urchueguía, M. Zacarès, J.M. Corberàn, Á. Montero, J. Martos, H. Witte, Comparison between the energy performance of a ground coupled water to water heat pump system and an air to water heat pump system for heating and cooling in typical conditions of the European Mediterranean coast, Energy Convers. Manag. 49 (2008) 2917-2923.

[11] L. Aresti, P. Christodoulides, G. Florides, A review of the design aspects of ground heat exchangers, Renew. Sustain. Energy Rev. 92 (2018) 757-773.

[12] H. Yang, P. Cui, Z.H. Fang, Vertical borehole ground source heat pumps: a review of models and systems, Appl. Energy 87 (2010) 16-27.

[13] M. Bortoloni, M. Bottarelli, Y. Su, A study on the effect of ground surface boundary conditions in modelling shallow ground heat exchangers, Appl. Therm. Eng. 111 (2017) 1371-1377.

[14] G. Gan, Dynamic thermal modelling of horizontal ground-source heat pumps, Int. J. Low Carbon Technol. 8 (2013) 95-105.

[15] M. Habibi, A. Hakkaki-Fard, Evaluation and improvement of the thermal performance of different types of horizontal ground heat exchangers based on techno-economic analysis, Energy Convers. Manag. 171 (2018) 1177-1192.

[16] M. Bortoloni, M. Bottarelli, On the sizing of a flat-panel ground heat exchanger, Int. J. Energy Environ. Eng. 6 (2015) 55-63.

[17] L. Gabrielli, M. Bottarelli, Financial and economic analysis for ground-coupled heat pumps using shallow ground heat exchangers, Sustain. Cities Soc. 20 (2016) 71-80.

[18] U.S. Department of Energy (DOE), Energy Savings from Dual-Source Heat Pump Technology, in: http://www.eren.doe.gov/femp.

[19] J.M. Corberán, A. Cazorla-Marín, J. Marchante-Avellaneda, C. Montagud, Dual source heat pump, a high efficiency and cost-effective alternative for heating, cooling and DHW production, Int. J. Low Carbon Technol. 13 (2) (2018) 161-176.

[20] I. Grossi, M. Dongellini, A. Piazzi, G.L. Morini, Dynamic modelling and energy performance analysis of an innovative dual-source heat pump system, Appl. Therm. Eng. 142 (2018) 745-759.

[21] K. Allaerts, M. Coomans, R. Salenbien, Hybrid ground-source heat pump system with active air source generation, Energy Convers. Manag. 90 (2015) 230-237.

[22] W. Yang, Y. Chen, M. Shi, J.D. Spitler, Numerical investigation on the underground thermal imbalance of ground-coupled heat pump operated in cooling-dominated district, Appl. Therm. Eng. 58 (2013) 626-637.

[23] W.B. Yang, J.L. Zhu, Z.Q. Chen, Investigation on the influences of underground thermal imbalance ratio on soil temperature variation of ground coupled heat pump, In: 7th International Symposium on Heating, Ventilating and Air Conditioning - Proceedings of ISHVAC, vol. 4, 2011, pp. 1334-1340.

[24] E. Wang, F. Zhang, Y. Zhang, Q. Zhao, Influence investigation of thermal load imbalance on geothermal heat exchanger, Proced. Eng. 205 (2017) 3846-3851.

[25] H. Wang, X. Liu, G. Feng, Z. Kang, Y. Luo, B. Bai, L. Chi, Simulation analysis of air-ground dual source heat pump operating efficiency, Proced. Eng. 121 (2015) 1413-1419.

[26] M. Cannistraro, E. Mainardi, M. Bottarelli, Testing a dual-source heat pump, Math. Model. Eng. Probl. 5 (3) (2018) 205-210. 
[27] M. Bottarelli, L. Zang, M. Bortoloni, Y. Su, Energy performance of a dual air and ground-source heat pump coupled with a Flat-Panel ground heat exchanger, Bulg. Chem. Commun. 48 (2016) 64-70.

[28] M. Bortoloni, Experimental Analysis and Numerical Simulation of a Flat-Panel Ground Heat Exchanger, Ph.D. Thesis University of Ferrara, Italy, 2016.

[29] https://energyplus.net/testing, Accessed 23 November 2018.

[30] C. Cuevas, J. Lebrun, V. Lemort, E. Winandy, Characterization of a scroll compressor under extended operating conditions, Appl. Therm. Eng. 30 (2010) 605-615.
[31] C. Cuevas, J. Lebrun, Testing and modelling of a variable speed scroll compressor, Appl. Therm. Eng. 29 (2009) 469-478.

[32] S. Shuaihui, Z. Yuanyang, L. Liansheng, S. Pengcheng, Simulation research on scroll refrigeration compressor with external cooling, Int. J. Refrig. 33 (2010) 897-906.

[33] COMSOL Multiphysics Reference Manual, 2017803-805. 